\title{
Developing Communication Among Science Student Teachers
}

\section{Loyola Pratheep}

Department of English, St. Joseph College of Engineering and Technology, Dar es Salaam, United Republic of Tanzania

\author{
Email address: \\ loyolap02@gmail.com
}

\section{To cite this article:}

Loyola Pratheep. Developing Communication Among Science Student Teachers. Science Journal of Education. Special Issue: Science Learning in Higher Education. Vol. 3, No. 4-1, 2015, pp. 1-4. doi: 10.11648/j.sjedu.s.2015030401.11

\begin{abstract}
Teachers in modern institutions are often amazed at learner's eagerness to learn, their creative problem solving, persistent efforts in self-development and their academic athletic and artistic activities. Trained teachers who are curious and scientifically oriented often wonder why and how they learn as much and even more effectively. It is the duty of the teachers to develop the constructive potentialities of every learner as fully as possible. The teachers should enable the learners to achieve an inquiring mind, skills for effective communication, learning for maintaining protecting and improving his health for satisfying entrusts and skills and ethical character. Communication is the occupational requirements of a job and many other activities. It is personal quality that enhances an individual's relations, job performance and career forecast. Communication relates to a person's ability to interact effectively with coworkers and students and is broadly applicable both in and outside the workplace.
\end{abstract}

Keywords: Communication, Student Teacher, Oral Communication, Verbal Communication

\section{Introduction}

A teacher's communication skill is an important part of their individual contribution to the success of an organization. Communication is increasingly required out by employers in addition to standard qualifications. It has been optional that in a number of professions communication skills may be more important over the long term than occupational skills. Teaching profession is one example where the ability to deal with students successfully and politely, more than their mere occupational skills.

\section{Student Teachers}

Student teachers are the students who study in teacher Education College, university or graduate student who is teaching under the supervision of a certified teacher in order to qualify for a degree in education. Communication will help them to improve their teaching skills. Student teachers are the learners who facilitate and enhance the knowledge of content and teaching skills. Thus, the integration of their communication by placing them at the center of classroom activities is more significant. Student teachers are to be a vital between the newer group of teachers, and older educators. The modern teaching philosophy and Traditional teaching philosophy respectively give importance to the communication of student teacher.

\section{Communication}

Communication is a two-way street. The best communicators adjust how they talk based on whom they're speaking to; with different style of communication. Communication has many implications in student teachers who may cover many aspects including listening, speaking, reading and writing. The growing importance of techno science and fields closely involved with markets with communication.

\section{Factors of Communication}

There are six factors of communication. They are:

What to communicate: The sender should aware of the content of communication. It should be useful for both the sender and the receiver.

When to Communicate: The sender should aware of the circumstances and time to be communicate.

Why Communicate: This decides the reason to communicate. If the sender feels to share the knowledge with 
the receiver he/she can communicate.

How to Communicate: The sender should decide the ways of effective communication. This could include pictorial representation, models charts which form a faster impression than continuous task.

Where to Communicate: This decides the appropriate place and time to communicate. The sender should conscious about the interest and attitude of the receiver.

To whom to communicate: The sender should have knowledge about the receiver so that it could be effective and useful.

\section{Types of Communication}

There are two types of communication. Oral/Non-verbal Communication and Verbal Communication

\subsection{Oral Communication}

It is a type of communication the message is transmitted through sound, signs and postures etc. The basic ingredients of this communication are clarity, accuracy, empathy, sincerity, relaxation, eye contact, posture and modulation of voice. It needs the four senses, i.e, audio, visual, touch and smell.

\subsubsection{Listening}

Listening specific information is very important. It is also valuable since it creates the necessary conditions in which the mind can get to work, to sort out, restructure and digest what is being said. It is all the basis of all human knowledge. Good listeners are liked by others because they satisfy the basic human needs of being heard and being wanted. People who listen well are able to separate fact from fiction, to cope effectively with false plagiarism and to avoid having others use them for personal gain. Listening is not only to the words but also the feelings and the message as a whole. While all human beings are poor listeners at times, some are poor listeners most of the time. It is necessary to evaluate the listening habits of student teachers, so that they can start treating symptoms. A person's listening will express his attitudes to other people as surely as the way the way which he speaks to them.

Clues for Effective Listening

i. Listen actively and objectively, empathy, understanding.

ii. Concentrate on the speech.

iii. Listen not only verbal instructions but also non-verbal expressions.

iv. Listen for the main ideas and supporting facts.

v. Make notes when it is appropriate without interfering with the communication process.

While listening the individual should improve their job performance, open door for ideas and thus encourages creativity, learning should be enhanced and job satisfaction should increase when there is a good listening and participating in the mutual trust.

\subsubsection{Speaking}

Speaking means exchanging or sharing the news, ideas, facts and information to others. The speech depends on the environment and need. Speech expresses the thoughts, feelings, opinions, beliefs and ideas. The expressions depend on the relationship between two or more individuals and it can be formal or informal. The facts, figures and the information collected through reading, listening are great importance while preparing a speech. The mental development of the speaker is an absolute part of the speech preparation. The speaker should develop the habit of thinking and generalization and continuously increase the knowledge and update the information. It is important to consider the time, occasion and the mood of the audience. The scope and purpose should be decided by the speaker.

Golden Principles

Avoid abstract terms: The speaker should not use abstract terms and phrases which are quite vague and cannot be understood easily by the audience. Instead, the speaker can prefer concrete terms which can be easily understandable by the audience. It is better to talk in a familier language than the unfamiliar language.

Be Brief: The speaker should follow a direct and straightforward method. A brief speech will convey a better impression on the audience than a lengthy speech.

Sincerity of Approach: The speaker should show sincerity towards the audience to win their confidence and faith.

Importance of Accuracy: The given information should be accurate. If the audience find a wrong information, they may not accept the accurate part of the speech.

Avoid ironic Language: A good speaker should always avoid the use of ironic Language.

Choice of Words: A speaker should increase the vocabulary and word power deliberately. The freshness and newness of words at right place right time should help the speaker to develop confidence.

Use of Humour: Humour is an essential part of a speech if it used in appropriate place as spontaneously and sparingly.

\subsection{Verbal Communication}

It is a type through a written message. It is usually formal and follows strict rules of grammar. It is also used for communication between two friends and at the same time used for filling the applications. It can also pictorial or symbol based and does not involve spoken language.

\subsubsection{Reading}

"It is the good reader makes a good book" said R.W. Emerson. Reading is a important skill in communication. Good reading is listening in action, giving time and thoughtful attending the reading material and remaining alive to all the possibilities it suggests. . Helping the student teachers to read carefully and usefully is significant.

\subsubsection{Writing}

Writing is an art. For developing such an art, one must collect information, analyze it and the present it with their 
own views. Words have definite and exact meanings. Effective communication depends upon learning these definite and exact meanings and putting them into practical use. The meaning of a word changes depending upon the occasion. Writing is for others to read and understand. The problem of communication is much greater in writing than speaking. When speaking, one can watch others expressions and adjust the speech accordingly. But in writing, one cannot find others expressions and doubt. The whole message must be ascertainable from the written words alone.

Rules for effective Writing

i. The writer should have the knowledge about the audience, so that one can highlight the important points.

ii. It should be totally productive, objective and winning arguments.

iii. Write in paragraphs with subtitles.

iv. Prefer the familiar, concrete, simple and short words.

v. Make the writing interesting, selective and in short paragraphs.

vi. Clear writing begins in the mind.

vii. Follow the elements of writing as structure, layout, content, style, diction and flow.

viii. Remember that writing clearly, simply and understandabily is a demanding skill. It takes a lot of hard work to master the art of communication using written word.

\section{Significance of Communication for Student Teachers}

The good policy for both written and verbal communication are clear and concise along with concrete, correct, coherent, complete, and courteous. Improving the quality of education depends on first improving the recruitment, training, social status and conditions of work of teachers; they need the appropriate knowledge and skills, personal characteristics, professional prospects and motivation if they are to meet this expectation placed upon them (UNESCO Report, 1996: 141- 142). Though student teachers are the future teachers' communication is essential to them.

The importance of student teacher as an agent of change, promoting understanding and tolerance has never been more obvious than today. The need for change, from narrow nationalism to universalism, from ethic and cultural prejudice to tolerance, understanding and pluralism, from autocracy to democracy in its various manifestations, and from a technologically divided world where high technology is the privilege of the few to a technologically united world, places enormous responsibilities on teachers who participate in the molding of the characters and minds of the new generation. The stakes are high, and the moral values formed in childhood and throughout become particular importance. The concept of communication development constitutes the major thrust of all education and training programs.

\section{Why Science Student Teachers}

Science is very important for the real life. One cannot live without science. So science teachers should be well communicators probably so that they can able to make the learners understand and analyze the concepts, information effectively. So as higher education learning conditions one should give more importance for the future teachers. In describing the methodology of developing communication among science student teachers, one can note characteristics that define them. In traditional teaching methods, there is a high emphasis on attending lectures, reading texts, and solving problems. In modern teaching methods, there is a high quality put on developing one's unique knowledge through the pursuit of the scientific observation and findings. Another hallmark of the modern teaching approach is the incorporation of technology, a highly useful skill that is required of most who intend on entering the job market in future years. Most schools are equipped with smart boards and include roaming laptop carts that allow all students, gain experience with the communication that will make them successful in the next steps of their lives. Science education activities should enhance children's understanding of the role communication plays in the development of scientific understanding. Self communication as we rationalize and make sense of experiences and meta-cognition used to evaluate others ideas and thoughts are essential competencies that need to be valued elements of science education programmes. The importance of developing the skills of communication in science activities cannot be underestimated. The same can be said for having knowledge of communication tools available and their suitable use.

The overall goal of science education can be viewed as providing the future citizens with the opportunity to develop the knowledge, skills and attitudes encompass in the idea of scientific literacy. If this is achieved they will be able, as informed members of society, to participate in well-versed decision-making about scientific phenomena and issues affecting them and the communities they live in.

\section{Barriers in Communication}

In any communication, there are at least two sets of desired purposes. The purpose from the communicators point of view and from the receiver's point of view. When the communication purpose of the source and the receiver are complementary, communication can continue. If it is incompatible, communication breaks down. There are six major barriers in communication.

i. Ineffective Environment: The environment created by the communicator influences his effectiveness. The cultural, educational, occupational and other personality differences would affect his effectiveness of communication.

ii. Inaccurate Symbols and Efforts: The gestures, language may affect the communication. Lack of preparation and organization also may affect effective communication 
iii. Incompleteness of Communication: If the sender makes assumptions on the context makes incompleteness of the communication.

iv. Transmission of Message: The proper channels of physical distortion, technical problems, handling media and liable constrains may lack the communication.

v. Problems Related to the Receiver: Lack of attention and interest, lack of knowledge, attitude towards the context physical fitness, and emotions may lack the communication.

Mobility of persons and profession and its impact on life style affects communication. Education, expanded enormously, largely in response to demographic change. Teacher education is directed away from its traditional concern with the liberal education of undergraduates.

The new developments in the world of teacher education closely implied by and affected by globalization, quality assessment, quality assurance and accreditation and recognition of qualifications. Throughout the world, the concept of lifelong learning has gained currency as a strategy for pursuing the knowledge and skills that are needed to survive in a rapidly changing world. In terms of education and training, this means that studying has become an ongoing process and that learning and work-related activities are no longer seen as separate activities.

\section{Guidelines for Developing Communication}

To achieve the goal, Student teacher communication development is embedded within the vision and mission of teacher Education, has identified the following guidelines:

- Build capacity/critical mass with a view to develop in students certain targeted skills, knowledge and attitudes.

- Work collaboratively with members of the academic staff community to ensure teaching and learning experiences of high quality.

- Design and implementation of an overarching framework for skills development.

- Encouragement of self-reflective teaching practice and learning.

- Promotion of action learning and action research as a strategy for student teacher's development.

- Promotion of inter-departmental and inter-students cooperation.

- Support and collaboration with existing services and programme initiatives to support and develop student's communication skill.
- Finally, the best thing we can do to improve the communication skills is to learn to really listen-to pay attention and let the other person talk without interrupting.

\section{Conclusion}

The outlook of education should be based on the principle of emphasizing correct values. Democratic values, group responsibility, tolerance, co-operation, mutual understanding should be developing in the mind of the student teachers only by good communication skills. Thus, teacher education can improve their science students as well citizens of the society and a good teacher for the future.

\section{References}

[1] Anitha \& Abraham. (2001). Practical Communication: Communicative English LSRW-2000. Kumbakonam: Anuratha Agencies.

[2] Dayal, Deepak. (2007). Modern methods of teaching physics. New Delhi: APH Publishing Corporation.

[3] English for engineers and Technologists (2006). Thomas Valley University, United Kingdom \& Anna University

[4] Kaur, Jaskiran Vir. (2008). A text book of teaching of social studies (2nd Ed.). Luthiana: Tandon Publication.

[5] Lakshminarayan, K.R (2004). English for technical communication. Chennai: SciTech Publications Pvt. Ltd.

[6] Assessing Your Teaching. Center for Teaching \& Learning Excellence, the University of Utah. Accessed 26 January 2010 http://www.ctle.utah.edu/?\&pageId=2009

[7] Austin, Evaluating Your Teaching: How Did I Do? University of Texas Libraries, Retrieved from http://lib.utexas.edu/services/instruction/t ips/eval/eval teach.html on 26 May 2013.

[8] Bhatt, B. D \& Sharma, S. R. (2005). Educational Technology. Concept and technique. New Delhi: Kanishka Publishers.

[9] Bonwell, C.; Eison, J. (1991). Active Learning: Creating Excitement in the Classroom AEHE-ERIC Higher Education Report No. 1. Washington, D.C.: Jossey-Bass. ISBN 1878380-08-

[10] Carter, V. Good (1945). Dictionary of Education. New Yark: MC Graw-Hill Book Company

[11] Centra, John A. (1993). Reflective faculty evaluation: Enhancing teaching and determining faculty effectiveness. San Francisco: Jossey-Bass. 